\title{
ACCELEROMETRIC DATA AND WEB PORTAL FOR THE VERTICAL CORINTH GULF SOFT SOIL ARRAY (CORSSA)
}

\section{Kassaras I. ${ }^{1}$, Roumelioti Z. ${ }^{2}$, Ktenidou O.-J. ${ }^{3}$, Pitilakis K. ${ }^{2}$, Voulgaris N. ${ }^{1}$ and Makropoulos K. ${ }^{1}$}

\author{
${ }^{1}$ University of Athens, Department of Geophysics-Geothermics, 15784, Panepistimioupoli - \\ Zografou, Athens, Greece, kassaras@geol.uoa.gr, kmacrop@geol.uoa.gr \\ ${ }^{2}$ Aristotle University of Thessaloniki, Department of Civil Engineering, P.O. Box 424, 54124, \\ Thessaloniki,Greece,zroum@auth.gr,kpitilak@civil.auth.gr \\ ${ }^{3}$ Helmholtz Centre Potsdam, GFZ German Research Centre for Geosciences, 14467, Potsdam, \\ Germany,olga.ktenidou@gmail.com
}

\begin{abstract}
Strong motion data recorded during the 15-year operation of the CORinth Gulf Soft Soil Array (CORSSA) in the highly seismic region of Aegion have been homogenized and organized in a MySQL database. In the present work we describe the contents of the database and the web portal through which these data are publicly accessible. CORSSA comprises one surface and four downhole 3-D broadband accelerometric stations. It was installed in 2002, in the framework of European project CORSEIS, aiming at gathering data for studying site effects, liquefaction, and non-linear behaviour of soils, as well as earthquake source properties. To date, the array has recorded 549 local and regional events with magnitudes ranging from 1.1 to 6.5. Although the vast majority of the recorded events caused weak ground motion at the CORSSA site, the scientific value of the data set pertains to the sparsity of this kind of infrastructure in most parts of the world.
\end{abstract}

Keywords: site effects, strong motion database, earthquake.

\section{Пєрí $\lambda \psi \eta$}

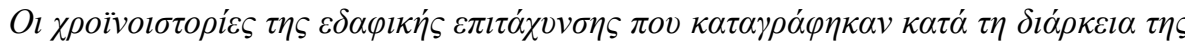

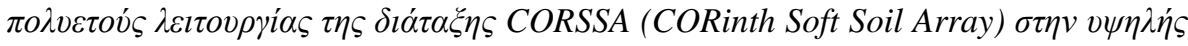

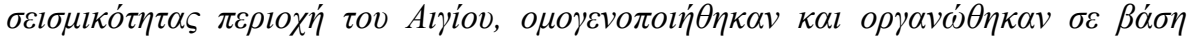

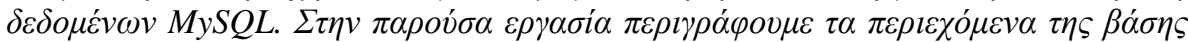

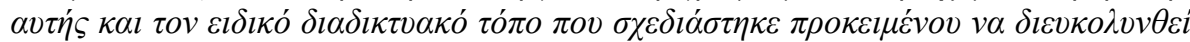

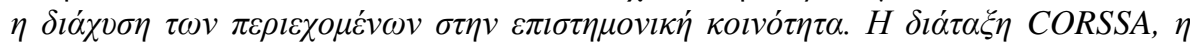

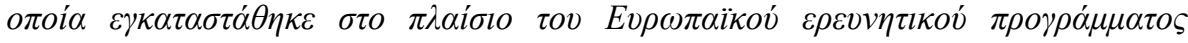

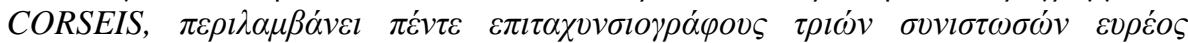

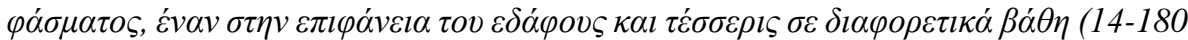

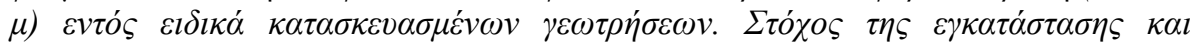

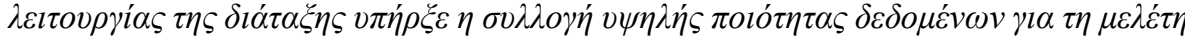

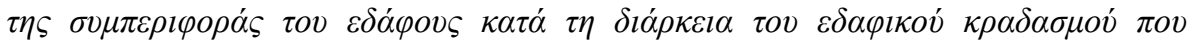

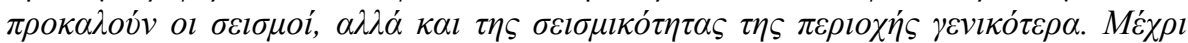

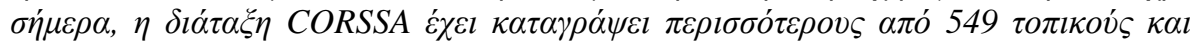

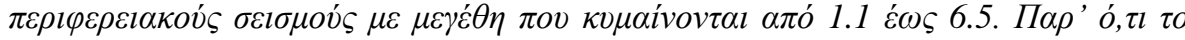




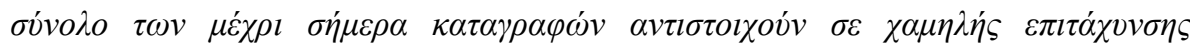

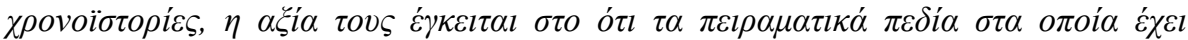

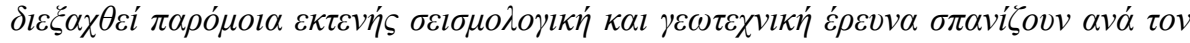
кó

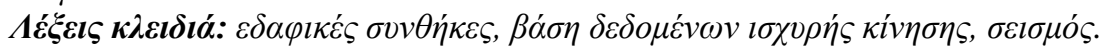

\section{Introduction}

The major task in seismological research is the understanding of earthquake phenomena and their consequences to the natural and anthropogenic environment, with the purpose of mitigating the latter by providing valid and timely information to be used for effective earthquake planning and decisionmaking processes. This requires reliable in situ observations combined with innovative analyses and adequate interpretation. Given that data processing has presently become largely feasible through open-access modern computer codes, the reliability of the results depends mostly on the availability, quality and quantity of data obtained through direct observations. The accessibility of these data from a wide range of experts including individual researchers and research institutions can encourage diversity of analysis and promote new studies with societal benefits.

Site response crucially impacts the characteristics of strong ground motion, and hence its realistic assessment is essential for earthquake design, especially in regions with a high seismic potential. Site effects are increasingly documented through a growing number of sites instrumented with vertical downhole seismic arrays globally. The CORinth Soft Soil Array (CORRSA) is such an installation situated in Aegion (Figure 1), a city in the Gulf of Corinth - one of the most seismically prone areas in Europe. The present work seeks to meet the demand for 3-D ground motion observations of high quality and density, made available in formats that are compatible with enduser needs. This paper describes the structure, capabilities and prospects of a web portal for the accelerometric recordings at CORSSA. This work was developed by the Seismological Laboratory of the University of Athens and the Department of Civil Engineering of the Aristotle University of Thessaloniki.

The web application presented herein provides an advanced framework to access the raw and expertprocessed CORSSA recordings in formats compatible with end-user requirements for further analysis, guidelines on the usage of the accessed data and definition of the nature of data files that are released.

\section{The CORSSA Array}

\subsection{History}

The CORSSA vertical accelerometric array is located within the premises of the "Ladopoulos" old paper factory, on the west coast of Aegion port (Figure 1). The broader region, i.e., the Gulf of Corinth, is considered a young asymmetric Rift which is deforming by one of the highest rates in the Euro-Mediterranean region, having a rich and long history of large and catastrophic earthquakes throughout the historical and instrumental era (e.g., Papazachos and Papazachou, 2003). CORSSA comprises an 18-channel digitizer equipped with 5 three-component broadband accelerometers; namely one surface station sheltered inside an appropriately designed vault, and four stations installed in boreholes at depths of 14, 25, 60, and $180 \mathrm{~m}$ (Figure 2). The array is complemented by two pore-pressure sensors at 6 and $14 \mathrm{~m}$ depth and three permanent surface accelerometric stations installed inside the city of Aegion, operated by the National Observatory of Athens (http://accelnet.gein.noa.gr/), the Institute of Engineering Seismology and Earthquake Engineering (EPPO-ITSAK; http://www.itsak.gr), and the Seismological Laboratory of the University of Athens (http://dggsl.geol.uoa.gr). CORSSA was installed in 2002, in the framework of the European Project CORSEIS (EVG1-CT-1999-00002H, funded after FP5-EESD; CORSEIS 2001, 2002) as a result of the cooperation of several European Universities (the reader is referred to 
http://dggsl.geol.uoa.gr/proj/en_corseis.html for a brief description of the project). It was developed to facilitate the study and modelling of the impact of the near-surface soil formations to the seismic wave field. It involves an infrastructure that has already served several scientific projects (http://crlab.eu) and motivated international publications (e.g., Pitilakis et al., 2004; Ktenidou et al., 2011, 2013, 2015).
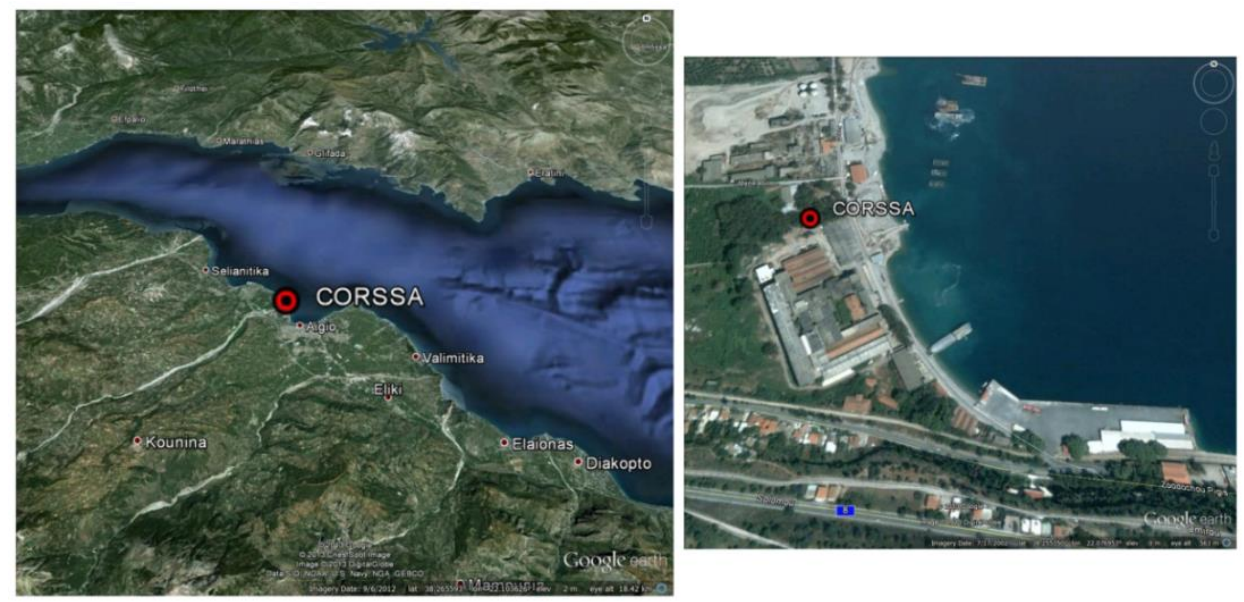

Figure 1 - Location of the CORSSA array, west of the Aegion port.

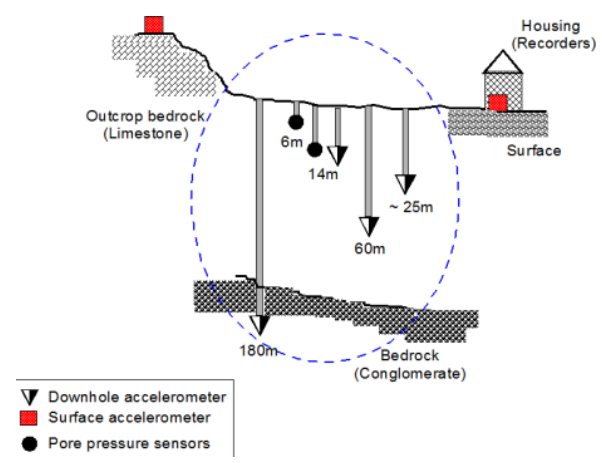

Figure 2 - Layout of the sensors at CORSSA (adapted from CORSEIS, 2001 2002).

\section{The Web Portal}

The design and technical aspects adopted for the development of the CORSSA database and its web portal (http://www.corssa.gr; Figure 3) were based on the pre-existing scheme used for a similar database, that of the EUROSEISTEST strong motion array in northern Greece (Pitilakis et al., 2013). All development tools used were Free/Open Source Software (F/OSS). The background programming language is Ruby, combined with the Rails web application framework (the combination often referred to as RubyonRails). Waveforms and metadata associated with the events recorded by CORSSA have been stored in a MySQL v5.5 relational database through a Content Management System (CMS). Prior to uploading to the MySQL database, data undergo routine offline processing regarding insertion and modification of metadata and basic signal corrections, mostly using the Seismic Analysis Code (SAC, Goldstein et al., 2003; Goldstein and Snoke, 2005). An administrator web interface was introduced, specially adapted for the application, facilitating the uploading procedure of data and metadata and minimizing the risk of mistyping and other user errors. A regular update of the database with newly recorded events and pertinent metadata can be performed promptly and easily. The application includes capabilities for quality graphics of velocity 
and displacement time histories, Fourier spectra, response spectra and spectrograms, computed and registered in an automated way. Several of the above options will be activated in the near future.

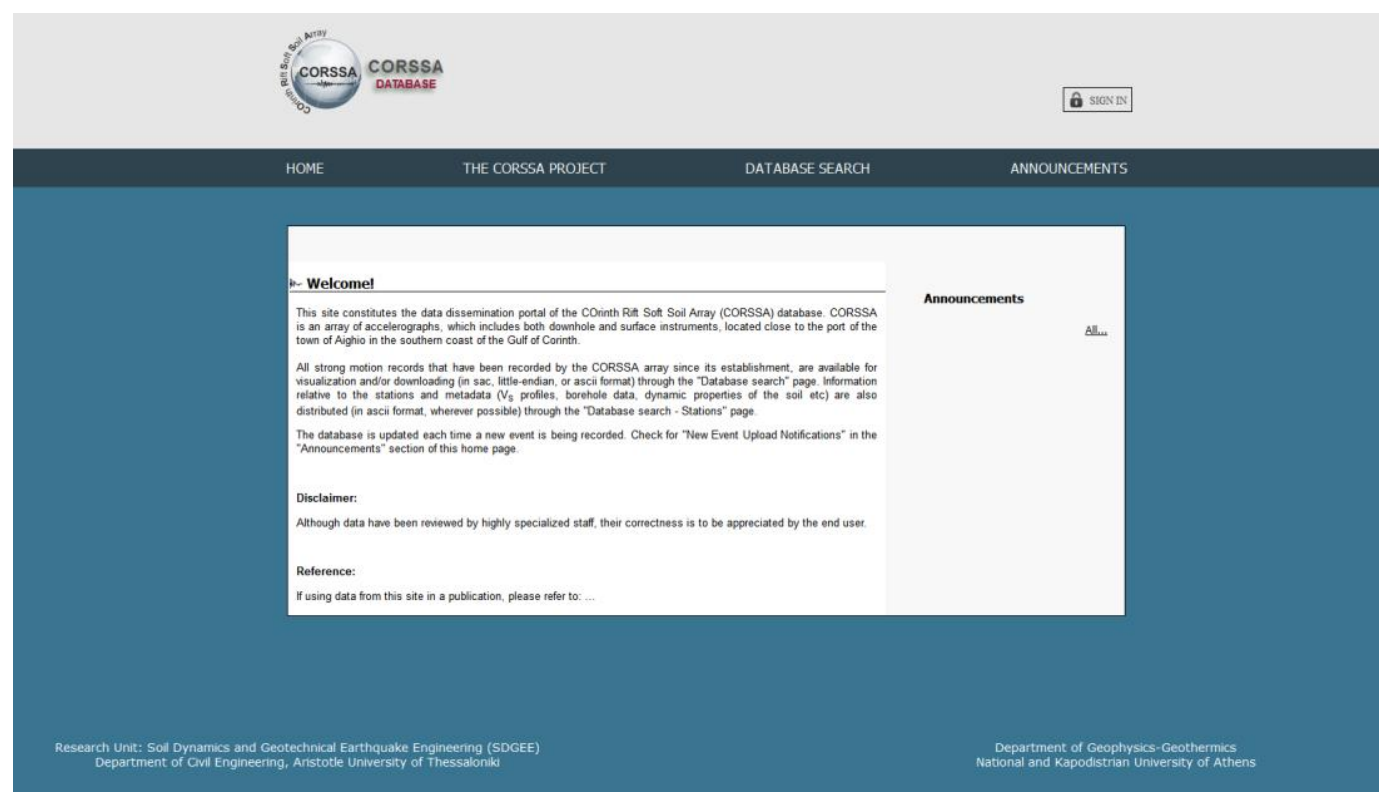

Figure 3 - The home page of the CORSSA web portal (at http://www.corssa.gr).

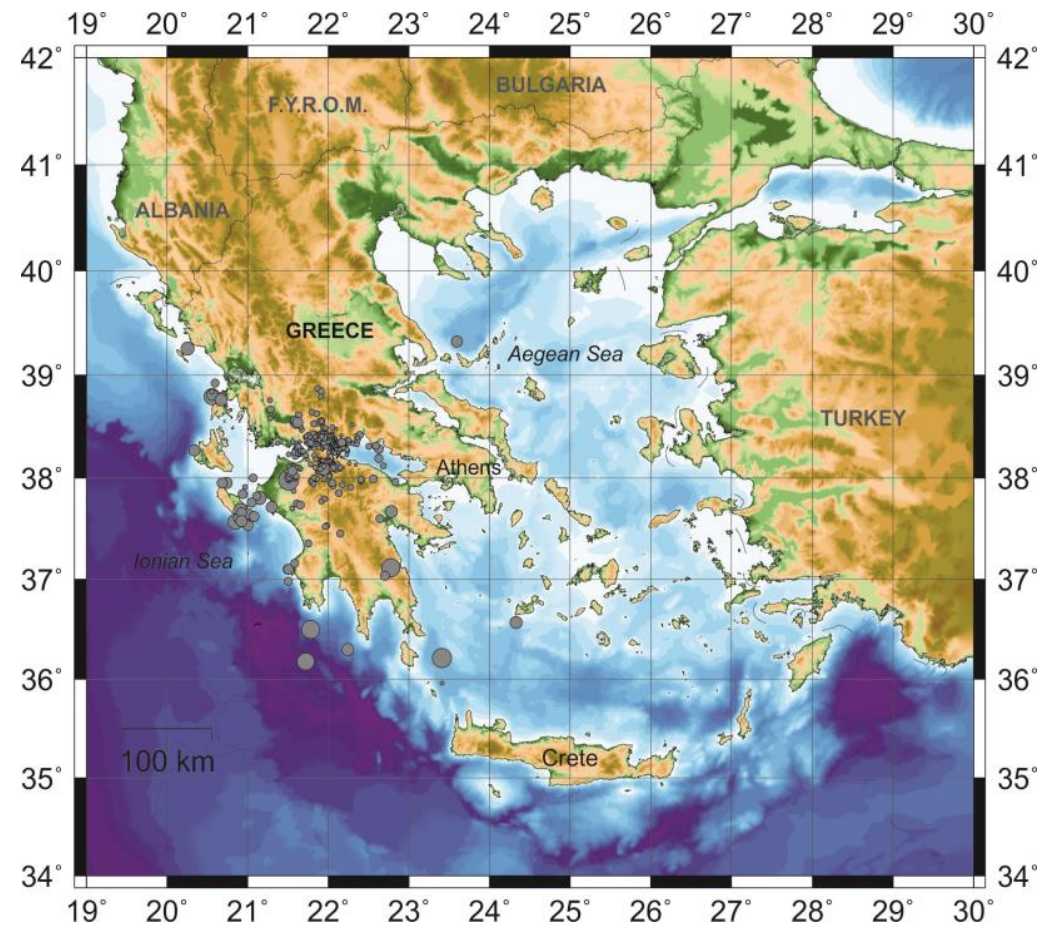

Figure 4 - Map of the event epicenters included in the CORSSA database.

Since its installation in 2002, CORSSA has recorded more than 1,000 seismic events, despite the fact that after the end of the CORSEIS project its operation was often disrupted either by technical 
problems or accidents. At present, the database includes 549 events out of the $>1000$ recordings (1647 single component recordings) of local magnitude $1.1 \leq \mathrm{M}_{\mathrm{L}} \leq 6.5$, at epicentral distances, $R$, between 1-280 km (Figure 4). The distribution of recorded events with $\mathrm{M}_{\mathrm{L}}, \mathrm{M}_{\mathrm{L}}$ versus epicentral distance $(\mathrm{R})$ and PGA versus R plots are presented in Figure 5. About 500 events recordings are under processing and they will be promptly included in the database.
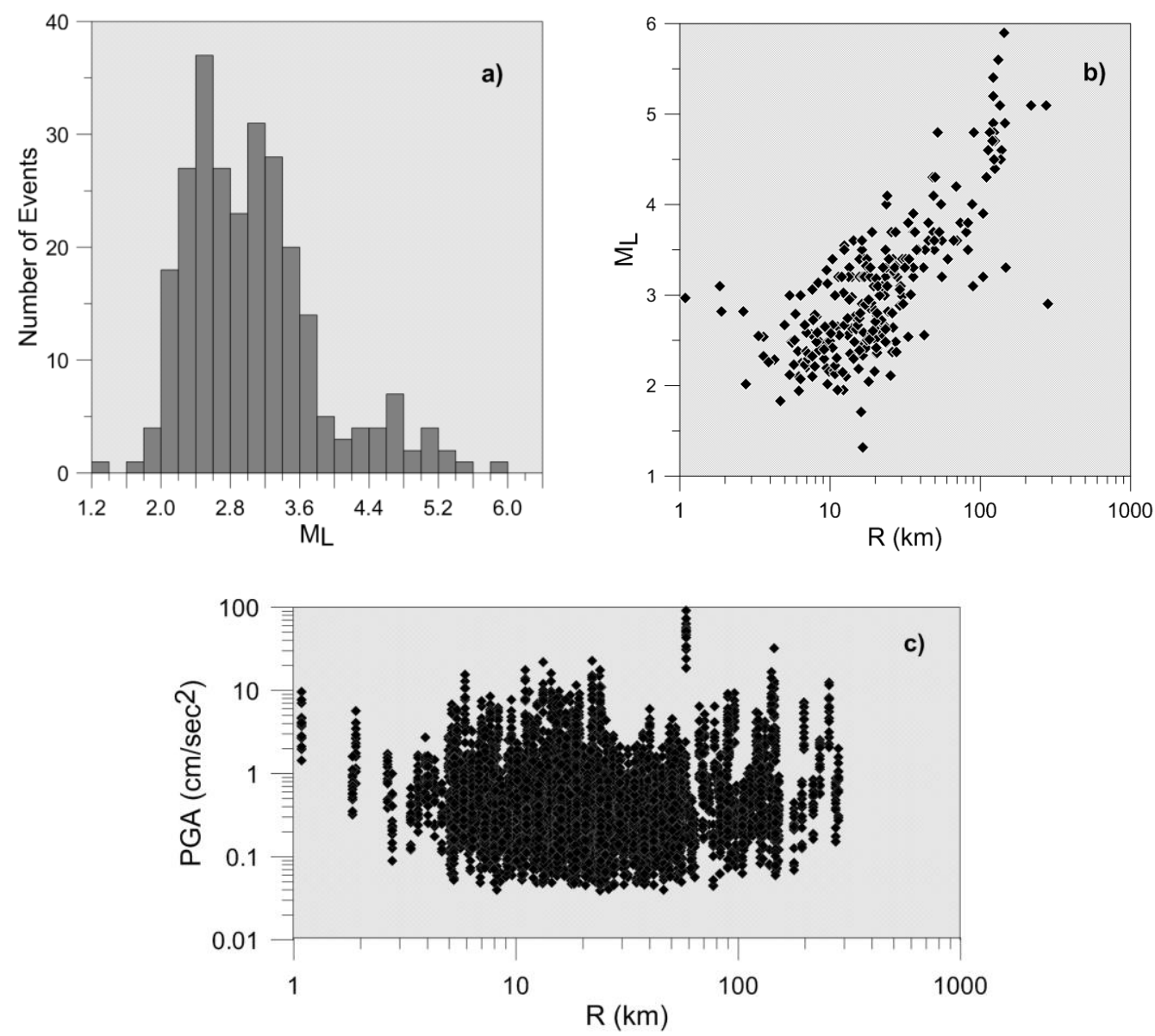

Figure 5 - Statistics on the contents of the CORSSA database. a) Number of recorded events per local magnitude, $M_{L}$, b) $M_{L}$ versus epicentral distance, and c) PGA versus $R$ for the 549 records in the database.

At present, the CORSSA web portal provides access to raw and routinely processed "Unfiltered" accelerometric data. "Raw data" correspond to the originally recorded waveforms without any processing. Waveform headers include all available information on the station and event location, component orientation (Ktenidou, 2010, 2015), absolute time, etc. "Unfiltered data" have been processed for non-standard errors, i.e. baseline offset and trend, spikes etc., and have been homogeneously oriented to the south-north and west-east directions by rotating the horizontal components. No filtering has been applied, in order not to distort the original signal amplitudes. In future, there will also be a "Filtered data" option, based on individual record processing and specific signal-to-noise criteria.

The CORSSA "Home" page provides links to general information, such as a description of the array, technical details, history information and scientific results available to date (Figure 3). Waveform data can be accessed and browsed under the "Database Search" option listed in the "Home" page, 
through three different platforms, following the common practice for similar databases (Pacor et al., 2011 and references therein) (Figure 6). The first platform contains search criteria related to the waveform records (i.e., peak ground motion values, distance from the earthquake source), the second one parameters related to the earthquake source (i.e., magnitude, location, type of faulting etc.), and the third platform allows for search based on station-related criteria (i.e., location, housing, soil category etc.). A combination of the three types of search criteria is feasible through the first platform.

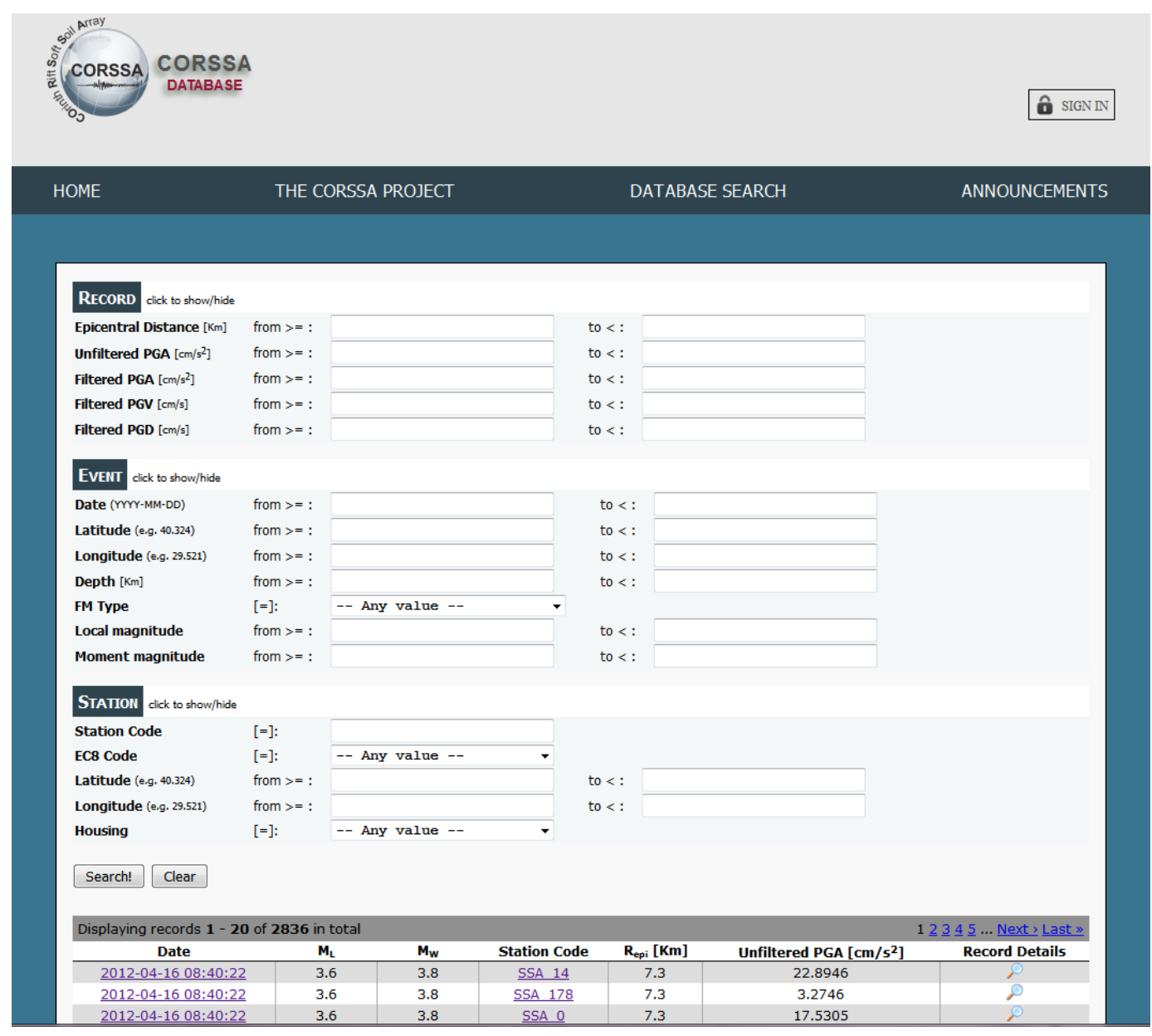

Figure 6 - Online form provided for searching the database contents. Three types of criteria (related to the acceleration record, the earthquake event or the recording station) can be used either individually or in combination. Query results are presented in the bottom of the page in the form of a table.

User queries result in a list of records that match the search criteria (Figure 6, see table at the bottom of the page). Each line, i.e., each record in the list, leads to a certain number of pages, which combine the requested waveforms and metadata in downloadable files and clickable screen plots, displaying tabulated station and event metadata, maps with epicenter locations (Figure 7), and plots of acceleration waveforms. Examples of such plots are shown in Figure 8. At the end of each search, the user can download the requested "Raw" and/or "Unfiltered" waveform data in either ASCII or SAC (PC-little endian) format, together with any associated graphic products. 


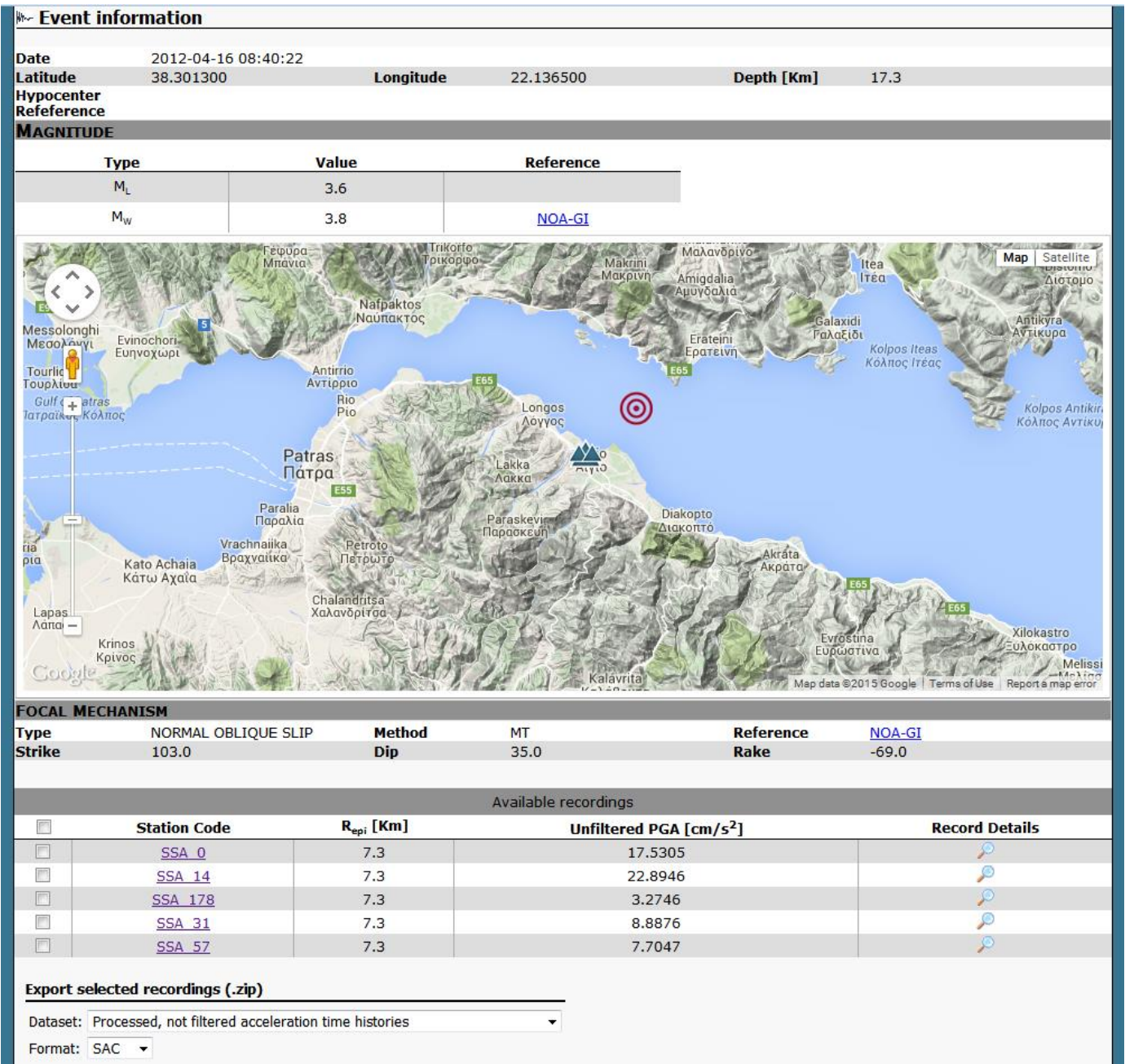

Figure 7 - Example of an event-dedicated web page. Apart from location and focal mechanism information, a map is provided with the locations of the epicentre and the recording station. At the bottom of the web page, a table summarizes parameters of the actual records and provides links ('Record Details') to the corresponding waveforms. A form for facilitating data download in SAC and ASCII format is also included ('Export selected recordings'). 
Har Waveform Plots - SSA_0 - N component

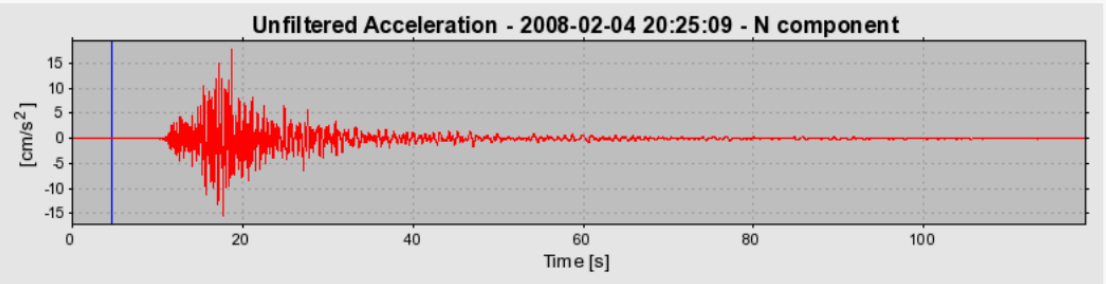

Ha- Waveform Plots - SSA_14 - N component

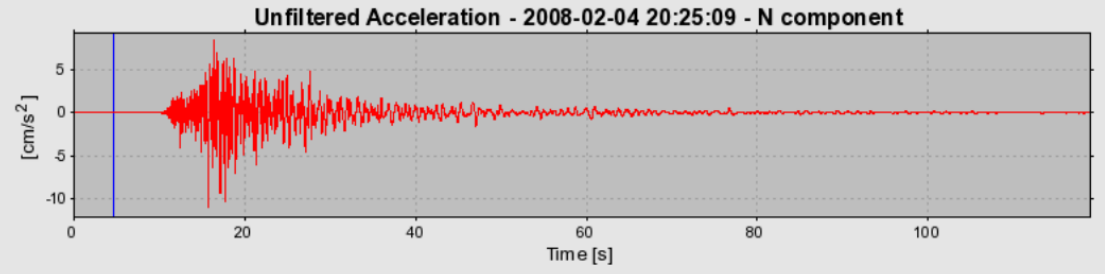

Ma- Waveform Plots - SSA_31 - N component

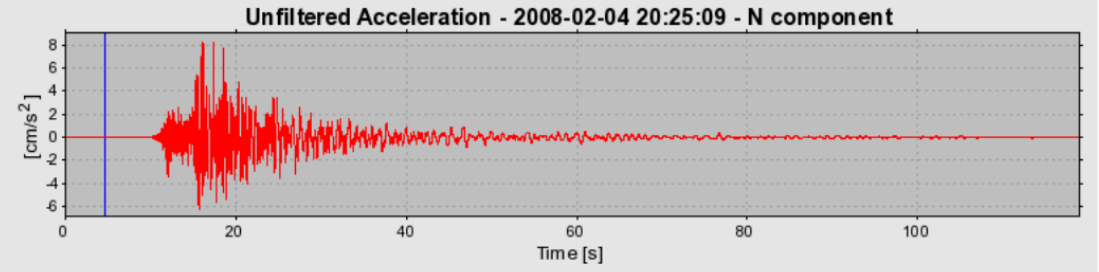

Have- Waverm Plots - SSA_57 - N component

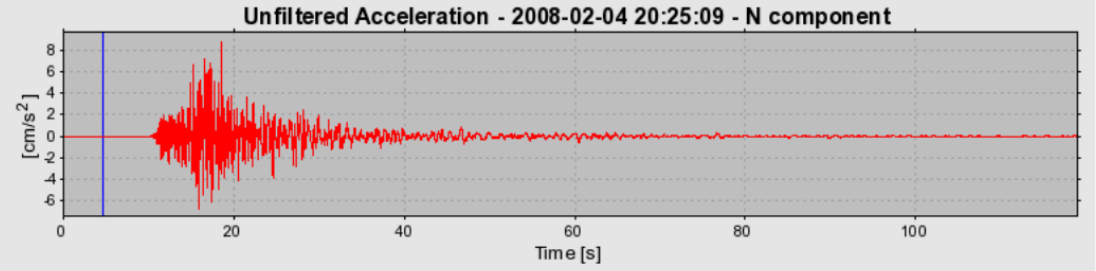

Have - Wavorm Plots - SSA_178 - N component

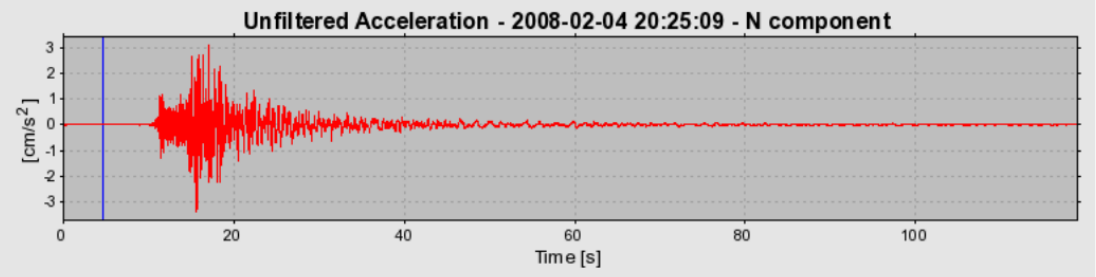

Figure 8 - Example plots of acceleration traces (M4.9, 04/02/08 in Northern Peloponnese) for the NS component, at all five stations of the array. 


\section{Discussion}

The CORSSA downhole array has been operating for over a decade in the highly seismic area of Aegion, Gulf of Corinth. It constitutes a significant infrastructure for seismological and geotechnical studies. The operation of the array so far, although often interrupted due to funding and technical problems has provided a significant data set of accelerometric data with a wide magnitude and distance range. These records have now been organized and are disseminated through a user-friendly web portal (http://www.corssa.gr). By creating and maintaining this portal, we aim to encourage maximum possible exploitation of the overall investment in the CORSSA site. The future task of the institutes currently responsible for this infrastructure (namely, the University of Athens and the Aristotle University of Thessaloniki), is to maintain it operational. Given the good existing knowledge in terms of seismotectonic and geotechnical background, this site will very likely provide significant records in the future. To ensure the continuous operation of the array and the high quality of future data, action has already been taken and CORSSA has been selected as part of the significant scientific infrastructure included under the HELlenic Plate Observing System (HELPOS), a project funded in the framework of the national roadmap for Research Infrastructures (RI) for the period 2014-2020 (http://www.gsrt.gr). The contribution of this work is the web portal presentation and data dissemination to scientific community. The online CORSSA database will be further enriched with more recent data and recordings from the RASMON strong ground motion network (Makropoulos et al., 1993).

\section{Acknowledgments}

The CORSSA array installation was funded by European research project CORSEIS and its maintenance by the CORSSA agreement between Aristotle University of Thessaloniki (AUTH), Greece; National Kapodistrian University of Athens (NKUA), Greece; and Institut de Radioprotection et de Sûreté Nucléaire (IRSN), France. We acknowledge with gratitude the help of all free/open source software developers that make their tools available to the scientific community and to the public at large. We are grateful to the numerous colleagues and technicians that faced all the hardships of the CORSSA array installation and maintenance throughout its many years of operation.

\section{References}

CORSEIS, 2001. 2nd-Year Scientific Report, An integrated study of seismic hazard assessment in the area of Aigion, Gulf of Corinth, Greece, EVG1-1999-00002, Laboratory of Soil Mechanics and Foundation, Civil Engineering Department, Aristotle University of Thessaloniki, Greece.

CORSEIS, 2002. Final Scientific Report, An integrated study of seismic hazard assessment in the area of Aigion, Gulf of Corinth, Greece, EVG1-1999-00002, Laboratory of Soil Mechanics and Foundation, Civil Engineering Department, Aristotle University of Thessaloniki, Greece.

Goldstein, P., Dodge, D., Firpo, M. and Minner, L., 2003. SAC2000: Signal processing and analysis tools for seismologists and engineers, Invited contribution to "The IASPEI International Handbook of Earthquake and Engineering Seismology”, In: Lee, W.H.K., Kanamori, H., Jennings, P.C. and Kisslinger, C., eds., Academic Press, London.

Goldstein, P. and Snoke, A., 2005. SAC Availability for the IRIS Community, Incorporated Institutions for Seismology Data Management Center Electronic Newsletter.

Ktenidou, O.-J., 2010. Experimental and theoretical study of seismic ground motion in the city of Aegion, Greece, focusing on local site and topographic effects, $\mathrm{PhD}$ Thesis, Aristotle University of Thessaloniki, $300 \mathrm{pp}$.

Ktenidou, O.-J., Chávez-García, F.J. and Pitilakis, K., 2011. Variance reduction and signal-to-noise ratio: reducing uncertainty in spectral ratios, Bull. Seismol. Soc. Am., 101(2), 619-634. 
Ktenidou, O.-J., Gelis, C. and Bonilla, F., 2013. A study on the variability of kappa in a borehole. Implications on the computation method used, Bull. Seismol. Soc. Am., 103(2a), 1048-1068.

Ktenidou, O.-J., Chávez-García, F.J., Raptakis, D. and Pitilakis, K.D., 2015. Site effects at Aegion, Greece, observed through the Corinth Soft Soil Array (CORSSA), Bull. Earthq. Eng., in review.

Makropoulos, K.C., Diagourtas, D., Voulgaris, N., Gariel, J.C., Dervin, P., Hatzfeld, D. and Wajeman, N., 1993. The western part of Gulf Corinth (Greece) strong motion network (RASMON), Preliminary results. $2^{\text {nd }}$ International Geophysical Congress, May 5-7, Florina, Greece, 1, 460-471.

Pakor, F., Paolucci, R., Luzi, L., Sabetta, F., Spinelli, A., Gorini, A., Nicoletti, M., Marcucci, S., Filippi, L. and Dolce, M., 2011. Overview of the Italian strong motion database ITACA 1.0, Bulletin of Earthquake Engineering, 9, 1723-1739.

Papazachos, B.C. and Papazachou, C.B., 2003. The Earthquakes of Greece, Ziti, P., Thessaloniki, Greece, (in Greek).

Pitilakis, K., Makropoulos, K., Bernard, P., Lemeille, F., Lyon-Caen, H., Berge-Thierry, C., Tika, T., Manakou, M., Diagourtas, D., Raptakis, D., Kallioglou, P., Makra, K., Pitilakis, D. and Bonilla, L.F., 2004. The Corinth Gulf Soft Soil Array (CORSSA) to study site effects, C.R. Geoscience, 336, 353-365.

Pitilakis, K., Roumelioti, Z., Raptakis, D., Manakou, M., Liakakis, K., Anastasiadis, A. and Pitilakis, D., 2013. The EUROSEISTEST strong ground motion database and web portal, Seism. Res. Lett., 84(5), 796-804. 